\title{
ASOCIACIONISMO DENDE ARRIBA: AS CÁMARAS AGRÍCOLAS EN GALICIA
}

\author{
Por \\ MIGUEL CABO VILLAVERDE
}

\begin{abstract}
As Cámaras Agrícolas constitúense en Galicia no cambio de século e ó longo de toda a súa existencia arrastrarán a tensión pola súa dobre natureza de órganos supostamente representativos dos intereses agrarios e pola outra de entidades semioficiais consultivas e extensión da Administración do Estado, de xeito que atoparán dificultades para definir a súa función e atravesarán sucesivas reformulacións lexislativas que por outra banda serán reflexo evidentemente de reformas na escala estatal. Froito do impulso renovador rexistrado no tránsito do século XIX ó XX, as Cámaras vanse involucrar nas transformacións que o sector agrario estaba a atravesar na Galicia do momento: se por unha banda colaboran na difusión de innovacións técnicas, notablemente no campo da mellora gandeira, pola outra tomarán partido nos debates sobre as formas de propiedade da tierra no contexto do asalto final ó foro. Ó mesmo tempo, dende o seu carácter semioficial tentarán canalizar o movemento societario nunha dirección ben determinada, en concreto por unha liña productivista e apolítica. A todo isto hai que engadirlle as grandes diferencias en canto ó seu grao de actividade entre as diferentes Cámaras, con frecuentes parénteses, ata o punto de que só a da Coruña rexistra unha continuidade que explica a atención preferencial que lle adicaremos.

As Cámaras Agrícolas no mereceron polo momento a penas atención por parte da historiografía galega, agás as referencias puntuais aportadas
\end{abstract}

"CUADERNOS DE ESTUdIOS GALLEGOS", Tomo XLVII, Fascículo 112, Santiago 2000. 
por José Antonio Durán ${ }^{1}$. Un obstáculo para o seu estudio ven dado polo feito de non ter sido localizados os arquivos nin os libros de actas de ninguna das que chegaron existir en Galicia, limitación que neste traballo, que por outra parte no pretende ser máis que unha cautelosa primeira aproximación ó tema, tentará ser subsanada recurrindo á prensa periódica e á publicística producida polas propias Cámaras.

\section{AAPARICIÓN DAS CÁMARAS AGRÍCOLAS}

As Cámaras Agrícolas créanse en virtude do Real Decreto do 14 de novembro de 1890 analogamente ás de Comercio, Industria e Navegación, establecidas catro anos antes. Segundo J. Pan-Montojo, o goberno puña co devandito decreto as condicións para a aparición dunha modalidade de asociación dominada polos grandes propietarios a modo de grupo de interese, de xeito que se configurasen como interlocutoras dos poderes públicos, ó tempo que reforzarían a alianza entre a grande propiedade e a Administración fronte ós restantes grupos compoñentes da sociedade ru$\mathrm{ral}^{2}$. A súa constitución habería que enmarcala no proceso de separación entre unhaAdministración pretendidamente técnica e os intereses privados.

$\mathrm{Na}$ altura de 1898 constituíranse vintesete Cámaras Agrícolas, cunha actuación que respondía sen embargo a parámetros ben diversos de acordo coas características do seu ámbito de implantación. Así, mentres nas rexións latifundistas eran un instrumento de dominio da grande propiedade rural, en Cataluña estaban hexemonizadas polos propietarios vitícolas no contexto do conflicto rabassaire e no Alto Aragón e Lérida pola pequena burguesía rural pronta a abrazar as teses costistas. Polo tanto, semella que o esquema previsto polo lexislador só se levou á práctica alí onde a estructura da propiedade estaba fortemente polarizada. ¿Que ocorría en Galicia, que vivía ademáis no cambio de século os inicios da mobilización agrarista?

' DURÁN, J.A. (1977), Agrarismo y movilización campesina en el país gallego (18751912), Madrid: Akal [de agora en adiante Agrarismo y movilización...].

2 PAN-MONTOJO, J. (1997), «La naissance des associations agraires en Espagne, 1833-1898», Histoire, Économie et Société, Año XVI, nº 2, pp.167-188. 
A primeira Cámara Agrícola que se constitúe en Galicia é a coruñesa, que o fai en 1896 pero só para desaparecer antes dun ano. En 1897 aparece a de Lugo, ó ano siguiente a de Mondoñedo³, en 1899 a de PantónMonforte (Lugo) con Joaquín Arias Sanjurjo como figura dominante, en 1900 a de Ourense $e^{4}$ e en 1904 a de Santiago. A da Coruña, que vai ser a que desenvolva maior actividade, será refundada en 1901. Aínda que como vemos algunhas delas xa se atopaban en funcionamento, as Cámaras Agrícolas galegas non van estar representadas nas sucesivas asembleas de Cámaras de Comercio de Santiago Alba e Basilio Paraíso nin na Asemblea Nacional de Productores organizada por Joaquín Costa en 1899 onde nace a Liga nacional de Productores, expresión do que se deu en chamar a rebelión das clases medias. Diversas cidades e vilas galegas estiveron presentes pero a través das Cámaras de Comercio e dos seus enviados reclutados de entre a burguesía crítica co sistema restauracionista dende posicións ideolóxicas republicanas ou rexionalistas. O eco do rexeneracionismo en Galicia tamén se manifestou na creación de Ligas de Productores contra a reforma fiscal diseñada polo político galego e eximio forista Villaverde, e a Unión Nacional contará precisamente en Pontevedra co seu primeiro órgano de periodicidade diaria. As actividades da Unión Nacional a escala estatal entre 1900 e 1901 atopan certa repercusión en Galicia en forma de folgas de contribuíntes, mitins... ata a consumación do seu fracaso a finais de 1901.

A diferencia do que ocorría en Aragón, as Cámaras Agrícolas non participarán nestas empresas que tiñan como obxectivo aproveitar o golpe

${ }^{3}$ En La Voz de Galicia (25-II-1899) infórmase de que un milleiro de propietarios e «labradores» dese Partido están a organizala e que xa terían conferido a súa representación na Asemblea de Zaragoza ó historiador rexionalista José Villaamil y Castro, aínda que non parece que finalmente asistise.

${ }^{4}$ Poidemos localizar o seu Regulamento, que deixa adiviñar aires transformadores, pois afirmábase por exemplo que se creaba «con el fin de fomentar los intereses de la agricultura, de la ganadería, de las industrias rurales, como asimismo el de defenderse contra los excesos de la administración pública de todos los grados y categorías de la región» $\left(\operatorname{art} .1^{\circ}\right)$, e entre as vías de actuación que consideraba estaba a de " [axitar] a opinión por medio de meetings de propaganda, á fin de levantar el espíritu público y avivar por este medio la atención distraída de los lectores». Como presidente aparecía o destacado republicano José Ogea, e como secretario Manuel Picouto, quizais o mesmo que sería tesoureiro da Federación Agrícola Provincial nos anos vinte dentro da Confederación Regional de Agricultores Gallegos liderada por Basilio Álvarez.

"CUADERNOS DE ESTUDIOS GALLEGOS", Tomo XLVII, Fascículo 112, Santiago 2000. 
moral do Desastre para promover unha transformación profunda do sistema político. Quizais esta falta de presencia directa das Cámaras Agrícolas se deba á tardía reconstitución da coruñesa, que en principio podería ser a máis proclive a adoptar posicións críticas co sistema dada a presencia no seu seo de significados líderes republicanos. Si convén salientar que na Asamblea de Valladolid a representación galega plantexou a incorporación ó programa da Unión Nacional a redención forzosa de foros, de aí a poucos anos un dos principais vectores de movilización do movemento agrarista, aínda que finalmente todo quedase nunha fórmula de compromiso debido entre outras cousas ás reticencias de Santiago Alba ${ }^{5}$.

\section{AS CÁMARAS AGRÍCOLAS EN BUSCA DA SÚA FUNCIÓN}

A traxectoria das Cámaras Agrícolas caracterízase pola súa irregularidade, con prolongados períodos de inactividade salteados en determinadas conxunturas por intentos de superar ese sopor coincidindo cun cambio na directiva ou ben con algún estímulo exterior. Ese estímulo podía ser social (exacerbación do conflicto foral, agudización da mobilización agrarista) ou ben reflectir intentos por parte dalgún goberno de replantexar o papel destas institucións.

Das Cámaras mencionadas anteriormente, só as de Lugo e A Coruña (e máis a de Santiago a partir de 1903) semellan non ter caído na inacción e conservado unha existencia que non fose meramente nominal ó pouco tempo de se fundar. As dúas Cámaras citadas están representadas no Congreso Agrario de Pontevedra de 1902, organizado pola Sociedad de Agricultores de Lérez, e que tivera como detonante a alarma perante a chegada a portos españois de gando arxentino e os rumores sobre a posible irrupción no mercado madrileño de carne conxelada da mesma procedencia. Ese mesmo ano creárase a Federación Agraria Municipal de Pontevedra no contexto da extensión do fenómeno societario e de todas as manifestacións que o rodeaban (prensa agraria, presentación de candidaturas nas eleccións locais, primeiras experiencias cooperativas, etc.) por toda a provincia. 'O Congreso acudiron ademáis trece sociedades agrarias, varias

${ }^{5}$ DURÁN, J.A., Agrarismo y movilización... páx.129.

"CUADERNOS DE ESTUdiOS GALLEGOS", Tomo XLVII, Fascículo 112, Santiago 2000. 
Cámaras de Comercio, as Sociedades Económicas de Lugo e A Coruña, as Federacións Obreira e Agrícola de Pontevedra capital e diferentes órganos de prensa. As conclusións aprobadas centráronse case exclusivamente en temas gandeiros, e prefiguran algunhas das que se convertirán en reivindicacións máis comúns nos medios agraristas e técnicos galegos nos seguintes trinta anos: mantemento ou mesmo elevación dos aranceis contra o gando estranxeiro, melloras no transporte ferroviario que facilitasen o abastecemento de gando galego ó resto de España, apoio da Administración periférica (Concellos e Deputacións) á mellora gandeira baseada ademais nas especies propias do país mediante o sostemento de Estacións Pecuarias, concursos e paradas de sementais, e por último reducción dos dereitos arancelarios sobre as importacións de millo destinado a forraxe $\mathrm{e}^{6}$. Á parte tomábase partido a favor do asociacionismo agrario, en concreto das sociedades de seguros mutuos de gando que proliferaban xa fose como entidades independentes xa como seccións de sociedades agrarias propiamente ditas, e tamén da creación de Cámaras Agrícolas «en las poblaciones de alguna importancia, solicitando del gobierno para las mismas la excepción de gravámenes y por el contrario toda clase de franquicias $\rangle^{7}$. Neste momento, polo tanto, Cámaras Agrícolas e asociacionismo agrario van da man, polo menos en tanto o campo de actuación deste último primase os aspectos técnico-cooperativistas sobre os político-reivindicativos.

O espíritu rexeneracionista que anima a actuación das Cámaras Agrícolas nestes anos non se manifiesta pois directamente no plano político senón no fomento da reforma técnica do agro galego, intervención que debemos enmarcar no contexto da revitalización da actuación do Estado neste campo, principalmente gracias á «resurrección» da Granxa Agrícola-Experimental da Coruña baixo a dirección de Marceliano Álvarez Muñiz (1897-1904), os primeros pasos das sociedades agrarias nese sentido e a aparición dunha prensa especializada que canalizaba as aspiracións de transformación non sempre bien encamiñadas dunha serie de

\footnotetext{
${ }^{6}$ En abril dese mesmo ano a Cámara Agrícola de Lugo xa se posicionara en contra do proxecto do goberno de rebaixar os dereitos arancelarios ás importacións de vacún, propoñendo como alternativa para aliviar a carestía da carne actuar contra os abusos do mercado madrileño e a reducción de intermediarios (El Independiente 24-IV-02).

${ }^{7}$ La Crónica del Trabajo ${ }^{\circ} 17$ (1-X-1902).
} 
entusiastas «agricultores a la moderna», profesionais de clase media na súa maioría ${ }^{8}$.

En canto a este último punto, a primera mostra de prensa agrícola fora o Boletín da Granxa coruñesa, aparecido en 1899, e entre as cabeceiras que poderíamos considerar aquí dúas delas están vencelladas a Cámaras Agrícolas: La Agricultura Gallega e Prácticas Modernas. A primeira viu a luz en 1900 en Lugo como órgano da Cámara Agrícola da cidade baixo a dirección do xefe do servicio agronómico provincial Darío Fernández Crespo, e difundíase con carácter gratuito entre os socios 9 . A segunda apareceu na Coruña en xaneiro de 1903 e durante dez anos se mantivo como a publicación do seu xénero de maior influencia, e de feito numerosas sociedades agrarias contábanse entre os seus máis de mil subscriptores e os seus artigos eran reproducidos asiduamente na prensa local e agraria. Prácticas Modernas actuará inicialmente como órgano non oficial da Cámara Agrícola coruñesa e en 1907 con carácter oficial, ata protagonizar ós poucos meses unha sonora ruptura que analizaremos máis adiante ${ }^{10}$.

Se analizamos a actuación de cada unha das Cámaras no período que precede á Guerra Europea comprobaremos que a coruñesa é con moito a máis activa, por diante da de Santiago, mentres a da lucense vai diminuíndo progresivamente a partir xa de 1900. Como hipótese, pódese adiantar a de que a consolidación da de Lugo se vise dificultada pola debilidade e carácter serodio do movemento agrarista nesa provincia, onde en realidade o ritmo de fundación de sociedades agrarias non se aviva ata o segundo

\footnotetext{
${ }^{8}$ Sobre estes temas resulta imprescindible FERNÁNDEZ PRIETO, L. (1992), Labregos con ciencia, Vigo: Xerais.

${ }^{9}$ Por desgracia non se coñece a localización de ningún exemplar e somentes podemos facernos unha idea a través dalgúns sumarios reproducidos na prensa diaria, con seccións como o Calendario Agrícola, Sección Oficial, Conocimientos útiles, Mercados ou Situación Agrícola, máis os artigos propiamente ditos, deles algún da autoría do polígrafo Amador Montenegro Saavedra, de ideoloxía tradicionalista e un habitual deste tipo de publicacións.

${ }^{10}$ Sobre a interesantísima experiencia de Prácticas Modernas pódese consultar, para unha análise máis detallada da que podemos permitirnos aquí, FERNÁNDEZ PRIETO, L. E CABO, M. (1998), «Agrarismo y regeneracionismo en la Galicia de comienzos del século XX. El discurso del regionalismo agrícola», Agricultura y Sociedad, e CABO, M. (1997), «Pensamento económico e agrarismo na primeira metade do século XX», IDEGA. Documentos de Traballo, Historia 3, Universidade de Santiago de Compostela.
} 
lustro do século ${ }^{11}$. O resto das Cámaras existentes en Galicia non semellan ter pasado dunha existencia nominal.

A Cámara coruñesa reorganízase como dixemos en 1901 e nun ano conta con 263 socios e xa realiza algún reparto de sementes selectas e adubos. En 1903 recibe unha subvención do Ministerio para o aluguer de arados modernos para xeneralizar o seu uso pero o ano transcorre entre debates sobre que modelo era o máis axeitado e sen que se faga efectivo o seu reparto. Si se reparten entre os socios pequenos lotes de variedades foráneas de pataca e adubos, un campo de actuación este último que centraba a actividade publicística do daquela secretario da Cámara José María Hernansáez, Catedrático do Instituto de Ensino Medio e primeiro representante para Galicia da empresa $\operatorname{Cros}^{12}$. Ese ano os presupostos ascenderan a 1.452 pesetas procedentes das cuotas de socios, ó que habería que engadir subvencións estatais para accións concretas ${ }^{13}$. A terceira parte desa cantidade ía destinada a gastos de persoal e o resto distribuíase en pequenas partidas sen unha orientación clara, o mesmo que nos do 1904 nos que o gasto se diseminaba na adquisición para o seu posterior reparto entre os socios de modestas cantidades de adubos minerais e sementes (pataca, remolacha, millo, ray-grass, trevo e piñeiro roxo).

'O final dese ano contaba a Cámara con 283 socios, dos que o $85 \%$ se concentraba no Partido Xudicial da Coruña, mentres en ningún dos restantes da provincia se chegaba ós dez socios, e de feito nos de Muros, Negreira e Ordes non se contaba con ningún. Cómpre subliñar sen embar-

\footnotetext{
" A parte da publicación de La Agricultura Gallega, a Cámara de Lugo promoveu xestións para a creación e dotación nesa cidade dun Campo de Demostración todavía en 1900 a través do deputado local Vázquez de Parga. En 1906 reaparece para se adherir á campaña organizada para impedir a rebaixa dos dereitos sobre as carnes importadas, pero non participa en cambio nos concursos de gando organizados en Lugo en 1906 e 1908 co que supoñemos que xa deixara de funcionar.

${ }^{12}$ Unha breve aproximación á biografía deste personaxe na voz correspondente, a cargo de Lourenzo Fernández Prieto, en FRAGA VÁZQUEZ, X.A. E DOMÍNGUEZ, A. (eds., 1993), Diccionario Histórico das ciencias e das técnicas de Galicia. Autores, 18681936, Sada: Ediciós do Castro, pp.177-178.

${ }^{13}$ Prácticas Modernas n 28 (15-II-04). Do desglose dos gastos dedúcese que o persoal a soldo da Cámara estaba constituído por un oficial de secretaría e un ordenanza. Para ter un punto de comparación, digamos que os presupostos ordinarios da Granxa da Coruña andaban nesas datas ó redor das 18.000 pesetas.
} 
go que se aceptara a inscripción en bloque dos 163 socios dunha sociedade de seguros mutuos de gando da parroquia de Anceis, no termo municipal de Cambre, veciño á capital provincial ${ }^{14}$. Esta apertura ás asociacións agrarias, neste caso quizais debida á influencia dalgún socio da Cámara residente nesa parroquia, non tivo continuidade e se cadra constituíu unha oportunidade perdida para superar as limitacións dunhas institucións que á postre rematarían esgotando o seu radio de influencia inmediata nun reducido círculo de propietarios acomodados que unicamente tiñan unha relación indirecta co cultivo da terra, como rendistas ou como moito en calidade de agricultores aficionados.

Entre os directivos da Cámara deses anos destaca a mestura entre republicanos como Santiago Casares Paz, caciques locais de distinto signo (Luciano Pita en Ortigueira, o futuro alcalde da Coruña e animador do Sindicato Agrícola de Curtis Sánchez Anido) e técnicos como o perito e colaborador sobre temas agrarios de La Voz de Galicia Vicente Fernández Torres.

En 1906 ocupaba a presidencia o Marqués de Loureda, Enrique Fernández Alsina, deputado en varias ocasións polo distrito da capital, vicepresidente das Cortes e encarnación da figura do propietario acomodado emprendedor e introductor das novidades agrícolas do estranxeiro, como ilustran as reportaxes adicadas á sua finca de San Pedro de Nós (Oleiros) en Prácticas Modernas. Do resto da directiva destacan os nomes de dous concelleiros da corporación local coruñesa. Por unha banda, como tesoureiro, José Gradaille Chao, concelleiro monárquico pero de traxectoria independente e moi respetado nos medios agraristas (mesmo pola anarquista Unión Campesina), director precisamente de Prácticas Modernas, orador en mitins solidarios en 1907-1908 e redactor dalgunhas das conclusións das Asembleas Agrarias de Monforte. Pola outra, en calidade de contador, Santiago Casares Paz, pai de Santiago Casares Quiroga e líder do sector do potente republicanismo coruñés que vai participar na Solidaridad. A estructura da Xunta directiva amosaba a vontade de superar os límites da capital e ampliar o seu ámbito de actuación, xa que contaba cun vocal representante por cada unha das cabeceras de Partido Xudicial. Entre eles

14 Esta circunstancia debeu de ser efémera xa que en febreiro de 1909 a Cámara contaba únicamente con 93 socios (El Eco de Galicia, 20-II-09).

"CUADERNOS DE ESTUDIOS GALLEGOS", Tomo XLVII, Fascículo 112, Santiago 2000. 
salienta Salvador Golpe por Betanzos, un dos representantes do rexionalismo de tendencia tradicionalista, activo organizador de sociedades agrarias de inspiración solidaria na súa bisbarra e andando o tempo presidente da Cámara. A vocalía de Ortigueira correspondía a Luciano Pita SánchezBoado, impulsor xunto co seu irmán Leandro do asociacionismo no Ortegal, e no persoal expoñente tamén da figura do propietario innovador ó converter o seu pazo nunha especie de granxa agrícola e parada con sementais suízos ${ }^{15}$. A presencia dos técnicos agronómicos estaba asegurada mediante as vocalías do director da Granxa Leopoldo Hernández Robredo e de José María Hernansáez. 'O ano seguinte o Marqués de Loureda renunciaría á presidencia e sería substituído polo membro do Centro Solidario coruñés Luciano Marchesi ${ }^{16}$.

A renovación da directiva de 1906 semella coincidir cun intento de reavivar a institución, que segundo a revista Prácticas Modernas levaba algún tempo «en estado de sopor», e con ese fin escolle como eixo das súas actividades a promoción da mellora da cabana a través dos concursos de gando, partindo da primeira experiencia do organizado en 1905 na Coruña. Para superar esta falta de pulso noméase unha comisión na que se integran entre outros os técnicos anteriormente citados e Valeriano Villanueva, un dos peares de Prácticas Modernas e definidor ó longo de catro décadas dun orixinal discurso campesinista ${ }^{17}$. Ese mesmo ano subvenciónase con 125 pesetas o concurso de gando de Ortigueira, primeiro que será dunha larga serie, e con igual cantidade o de Betanzos. Na capital provincial a Cámara coorganizará xunto coa GranxaAgrícola un segundo concurso de gando no que, seguindo as orientacións propugnadas por Bartolomé Calderón e Valeriano Villanueva dende Prácticas Modernas se primarán as razas do país, poñendo fin ós cruces indiscriminados da etapa precedente, e accedendo en todo caso a cruzamentos meditados con

${ }^{15}$ ROSENDE FERNÁNDEZ, A.M. (1988), O agrarismo na comarca do Ortegal (1893-1936), Sada: Ediciós do Castro, páx.47.

${ }^{16}$ La Voz de Galicia (13-I-1907).

${ }^{17}$ Prácticas Modernas $\mathrm{n}^{\circ} 74$ (15-I-06). Sobre a figura de Valeriano Villanueva, a antoloxía de textos recopilada e comentada por J.A. DURÁN (ed., 1984), Organización del cultivo y de la sociedad agraria en Galicia y en la España Atlántica, Madrid: Xunta de Galicia e MAPA, e o inédito recentemente publicado Los grandes problemas del campo (Xunta de Galicia, 1998).

"CUADERNOS DE ESTUDIOS GALLEGOS", Tomo XLVII, Fascículo 112, Santiago 2000. 
razas afíns como a Simmenthal suiza e tendo como obxectivo último a consolidación dun vacún de aptitude mixta (carne, leite e traballo) que respondese ás necesidades do policultivo practicado polo campesiñado realmente existente ${ }^{18}$. Gracias ás xestións do concelleiro e membro da Directiva Gradaille, o Concello coruñés comprométese a adquirir dous reproductores de raza galega para que a Cámara organice a súa propia parada, así como dous verracos de raza celta.

Durante os anos anteriores, dende Prácticas Modernas se insistira machaconamente na necesidade de impulsar concursos dirixidos ós gandeiros e que primasen as variedades do país, non só atribuíndolles un valor en si mesmos na mellora gandeira senón unha función pedagóxica tanto para que os campesiños tivesen experiencia de primeira man das recomendacións dos expertos (por exemplo para que se concienciasen da necesidade de cruzar as vacas con reproductores de calidade e tamén apreciasen a calidade das súas reses mediante a obtención de premios), como igualmente para que as clases ilustradas concentrasen o seu interese en actividades productivas e non en ocupacións ociosas (aquí entraba en xogo a recorrente contraposición coas corridas de touros e os seus presuntos efectos embrutecedores).

Co propósito de profundar nesa mesma liña, a Cámara Agrícola convértese legalmente en 1907 en Sindicato para acollerse ás vantaxes previstas pola lei de 1906. Simultaneamente renova a súa directiva, na que salienta a presencia como vocal do principal líder republicano da cidade, José Martínez Fontenla, contrario a participar na Solidaridad Gallega, e como secretario doutro colaborador de Prácticas Modernas, Casimiro Fernández, especializado en temas gandeiros. Así mesmo, creábanse seis comisións que deberían canalizar as iniciativas que ambiciosamente se listaban nos novos estatutos. Esas comisións, con repetida presencia de técnicos (Hernández Robredo, Hernansáenz), eran as de Crédito Agrícola, Gandería, Concursos, a de Máquinas, Semillas e Prantas, a de Campos de Experimentación e Abonos e a de análises químicos, que supoñemos

\footnotetext{
${ }^{18} \mathrm{O}$ feito de que no Concurso de 1905 se premiasen maioritariamente exemplares de razas estranxeiras pertencentes a personaxes ilustres dera lugar a fortes críticas en Prácticas Modernas e foi correxido a partir do de 1906 precisamente a partir da incorporación á organización dos colaboradores da revista.
}

"CUADERnOS DE ESTUdiOs GALLEGOS", Tomo XLVII, Fascículo 112, Santiago 2000. 
dirixida a combatir o xeneralizado fraude no comercio de fertilizantes a parte da análise de terras ${ }^{19}$. En agosto de 1907 organiza un novo concurso de gando na Coruña baixo os mesmos parámetros.

En outubro de 1907 Prácticas Modernas anuncia que deixa de ser órgano da Cámara tras as críticas á liña da revista expresadas nunha xuntanza da directiva. Os colaboradores máis «ideolóxicos» de Prácticas Modernas, en especial Bartolomé Calderón, que era ademais corresponsal da Cámara en París, onde residía, distinguíranse dende a aparición da revista por unha linguaxe belicosa e directa na defensa das súas teses e por unha actitude de constante censura á Administración, os partidos turnistas e en xeral a todo o sistema político e institucional da Restauración nun ton inequivocamente rexeneracionista ${ }^{20}$. Contrarios ó centralismo en tódalas súas manifestacións (incluída a organización dos servicios agronómicos) e á opción proteccionista imposta a raíz da crise finisecular, o Ministerio de Fomento (neses momentos ocupado polo conservador pontevedrés González Besada) é obxecto de renovados ataques por consideralo ó servicio da oligarquía latifundista e trigueira. Bartolomé Calderón subliña especialmente as competencias que o Ministerio estaba a poñer nas mans da Asociación General de Ganaderos del Reino [A.G.G.R.], que contaba na directiva da Cámara Agrícola con personaxes influíntes como Luciano Pita ou Sánchez Anido, pero moitos outros aspectos da política agraria (regulamento da Lei de Sindicatos, negociación de varios Tratados Comerciais) son criticados con igual dureza ${ }^{21}$. A pesar da presencia na Directiva da Cámara de destacados republicanos e solidarios, o peso dos técni-

${ }^{19}$ En 1908 creábase unha Caixa de Crédito Agrícola no seo do Sindicato-Cámara dirixida ós socios pero tamén ás asociacións agrarias. Polas referencias de que dispoñemos a caixa a penas tivo actuación práctica nin paliou polo tanto o endémico problema do crédito no agro galego.

${ }^{20}$ FERNÁNDEZ PRIETO, L. E CABO, M. (1998), «Agrarismo y regeneracionismo en la Galicia de comienzos del século XX. El discurso del regionalismo agrícola», Agricultura y Sociedad.

${ }^{21}$ V. a modo de exemplo os artigos de Calderón «Nuestro atraso agrícola es el efecto del fomento oficial», Prácticas Modernas nº107 (1-VII-1907), ou «Los Ganaderos del Reino contra la ganadería española», Prácticas Modernas n¹11 (1-IX-1907). Calderón apostaba por un reforzamento das asociacións agrarias e da sociedade civil galega en xeral que permitise sacar adiante as reformas socioeconómicas coa menor intervención posible do Estado.

"CUADERNOS DE ESTUDIOS GALLEGOS", Tomo XLVII, Fascículo 112, Santiago 2000. 
cos dos servicios estatais e o propio carácter semioficial da institución explican a ruptura con Prácticas Modernas e con ela a imposibilidade no sucesivo de calquera colaboración cun grupo de autores que estaba tendo un protagonismo decisivo no estudio e a divulgación das novidades agronómicas asumibles pola agricultura galega.

'O ano seguinte a Cámara organiza o cuarto concurso de gando da Coruña e o director de Prácticas Modernas abre a batería de críticas contra esa institución polas deficiencias do regulamento do concurso e as diferencias cos dos anteriores nos que colaborara a revista, e significativamente son secundadas dende o semanario Solidaridad Gallega e cos mesmos argumentos, presentando a oposición

«entre los que opinamos que los premios en metálico deben ser para los labriegos criadores de ganado y nó para los dueños de reproductores adquiridos en el extranjero por quienes con más o menos afición y dinero sólo representan lo hecho por otros; cuando ya se había llegado en los concursos de La Coruña á no dedicar ni un solo premio en metálico á los reproductores de razas para señoritos...en el programa actual vemos premios, en dinero, para razas extranjeras de pura sangre» $\aleph^{22}$.

A partir dese momento o asesoramento técnico para os concursos que organice a Cámara Agrícola buscarase, á parte por suposto dos técnicos presentes na Directiva, na Asociación General de Ganaderos del Reino, que tamén aportaba subvencións para os premios e a organización. A través de diferentes concursos rexionais e comarcais ó largo da década dos dez e principios dos anos vinte a Cámara coruñesa colabora na selección

\footnotetext{
${ }^{22}$ Solidaridad Gallega $\mathrm{n}^{\circ} 11$ (12-VII-1908); os comentarios de Gradaille en «El cuarto concurso de ganados de La Coruña», Prácticas Modernas n¹34 (15-VIII-1908), onde tras reivindicar o papel da revista na mellora gandeira ( $«$ Los Concursos de ganados, podemos decir que son, aquí, obra nuestra»), arremete contra os defectos na organización: a duración pasaba a tres días contra os dous anteriores, co que se multiplicaban os gastos para os participantes, premiábase a razas estranjeras puras e incrementábase a presencia de elementos oficiais en prexuízo de expertos independentes como se prefería anteriormente. Finalmente, a revista tilda o concurso de «completo fracaso» e sinala que dos 500 exemplares presentados en 1907 se pasara a só 200 (Prácticas Modernas n¹36, 15-IX-1908).
}

"CUADERNOS DE ESTUdIOS GALLEGOS", Tomo XLVII, Fascículo 112, Santiago 2000. 
en pureza das razas galegas de vacún combinada co cruzamento, en especial coa raza Simmenthal, e a partir de 1905 se foi así superando o modelo decimonónico de concurso concebido como ocasión festiva de lucimento dunha presa de gandeiros acomodados pero sen a menor repercusión práctica e carentes de respaldo científico e labor a largo prazo $^{23}$. Nesta tarefa a actuación da Cámara coruñesa foi complementaria da desenvolvida pola GranxaAgrícola, da que era director L. Hernández Robredo, presente como comprobamos na directiva da Cámara.

Ademais do labor na difusión de novidades, a Cámara coruñesa tentou avanzar cara a un obxectivo no confesado, como era o de «domesticar»o movemento agrarista provincial, que neses anos se movía en boa medida por parámetros non só á marxe senón opostos a todo o que representaban os partidos turnistas. A anarquista Unión Campesina, a acción dos solidarios como inspiradores das organizacións agrarias ou a influencia incipiente do socialismo na comarca de Betanzos contribuían a trazar un cadro nada tranquilizador para os partidos dinásticos, cun movemento agrario heteroxéneo nos seus aspectos ideolóxicos e organizativos pero que estaba atopando causas comúns (anticaciquismo, antiforismo) e dotándose nas sucesivas Asembleas Agrarias (dende a primeira de Monforte de 1908) dun programa de considerable madurez. Valeriano Villanueva, ó tempo colaborador da Cámara e de Prácticas Modernas, recoñece abertamente que ante esta espiral a Cámara coruñesa «intenta formar el núcleo para contrarrestar el movimiento societario campesino de resistencia», se ben con escaso éxito ${ }^{24}$. De feito no artigo $12^{\circ}$ do regulamento de 1901 da Cámara instábase ós socios a fomentar a creación de sindicatos agrícolas, como fixo en Santa Eulalia de Curtis o deputado e vocal Sánchez Anido. A Cámara tentou potenciar un societarismo agrario centrado nos aspectos técnico-cooperativistas e afastado dos aspectos directamente políticos e reivindicativos, involucrando a directivos de sociedades de seguros mutuos dos arredores da Coruña como xurados en sucesivos concursos de gando e facilitando mediante os seus contactos coa Asociación General de Ganaderos del Reino as tentativas de exportar directamente reses ós mercados consumidores de Madrid e Barcelona prescindindo de inter-

${ }^{23}$ FERNÁNDEZ PRIETO, L. (1992), Labregos con ciencia, Vigo: Xerais, páx. 268.

${ }^{24}$ Nun artigo publicado no Heraldo de Madrid o 13 de agosto de 1908.

"CUADERNOS DE ESTUdIOS GALLEGOS", Tomo XLVII, Fascículo 112, Santiago 2000. 
mediarios. En consonancia con esta tendencia, en 1909 prodúcese unha remodelación da Directiva coa disminución do elemento republicano (abandona a súa vocalía Martínez Fontenla) en beneficio de personaxes vinculados ós partidos dinásticos (Alfredo García Ramos, o concelleiro liberal José Folla Yordi, o alcalde conservador Ozores Pedrosa) e técnico (coa incorporación do enxeñeiro agrónomo Eguilior). Significativamente, a Cámara Agrícola solidarízase en 1909, ó ser feito oficial o seu cese tras a caída do goberno Maura, co gobernador provincial Crespo de Lara, que se distinguira na represión contra as sociedades agrarias solidarias e anarquistas en colaboración coas redes locais de poder do partido conservador ${ }^{25}$.

Se a actuación da Cámara coruñesa presenta un balance con luces e sombras pero co haber da súa colaboración na mellora gandeira, o da Cámara Agrícola y Pecuaria de Santiago é bastante menos satisfactorio. Xurdida a finais de 1903, a súa directiva controlábana homes do Partido Liberal, dominante no distrito, entre eles o deputado e representante da Asociación General de Ganaderos del Reino Felipe Romero Donallo e o deputado provincial liberal Casimiro Torre ${ }^{26}$. Entre os directivos había varios da Sociedad Económica de Amigos del País, da que viña en parte a duplicar as funcións, e o papel que na coruñesa xogaban os técnicos do Estado desempeñábano en Santiago os profesores da Escola de Veterinaria. Non existe polo tanto o grao de heteroxeneidade ideolóxica que en certos momentos distinguiu á Cámara da Coruña, reflexo indubidablemente das características da cidade ${ }^{27}$. Ata 1911 non é quen de organizar un concurso de gando en Compostela, que atopou continuidade ó ano seguinte, ámbolos dous dirixidos ó Partido Xudicial e máis ós termos municipais de Brión, Teo eAmes, que era a área na que se pretendía consolidar a súa influencia e tamén unha das máis descoidadas pola Cámara coruñesa. Sen embargo a partir de 1912 a Cámara compostelana entra nun perío-

\footnotetext{
${ }^{25}$ El Eco de Galicia (7-V-09).

${ }^{26}$ No seu regulamento excluíase expresamente dos cargos directivos e da voz e voto nas asembleas ós socios colonos e obreiros agrícolas que non pagasen máis de 150 pesetas anuais (cifra daquela moi respetable) por contribución territorial. Aínda que teoricamente o ámbito de actuación era toda Galicia, os directivos debían ser residentes en Santiago e só como posibilidade se deixaba aberta a porta á creación de seccións locais.

${ }^{27}$ Si convén sinalar que chegou a ser membro da directiva Luis Porteiro Garea, dirixente da Irmandade galeguista local e concelleiro en 1915 en virtude dun acordo entre liberais, conservadores e republicanos para aplicar o artigo $29^{\circ}$.
} 
do de inacción coincidindo coa presidencia de Casimiro Torre no que nin se celebran concursos nin se cobran sequera as subvencións concedidas polo Ministerio de Fomento e a Deputación ${ }^{28}$, ata que en agosto de 1918 organiza unha Semana Agrícola na Escola de Veterinaria xunto coa Asociación General de Ganaderos del Reino ${ }^{29}$. Cando en 1919 se constitúe unha Junta de Administración y Patronato que tente salvar da decadencia a Escola de Veterinaria, que á postre sería suprimida en 1924, nela están representados Romero Donallo pola A.G.G.R. e o catedrático de Dereito José Rivero de Aguilar como vicepresidente da Cámara, pero resultan inútiles os esforzos por poñer en contacto ó centro coas numerosas sociedades gandeiras do entorno compostelano ${ }^{30}$. A Cámara de Santiago non conseguiu nin se propuxo sequera convertirse en coordinadora e portavoz das esperanzas e reivindicacións do agrarismo da súa zona de influencia, principalmente por ser expresión dos sectores propietarios e rendistas que desconfiaban -non sen razón dende o seu punto de vista- da organización do campesiñado.

Cara a 1915 existían en España segundo as estatísticas oficiais 125 Cámaras, das que seis corresponderían a Galicia: tres na provincia da Coruña, as de Monforte e Lugo e a de Pontevedra, da que non nos consta a data de fundación nin reflexo da súa actividade na prensa provincial ${ }^{31}$.

${ }^{28}$ Así o denuncia o semanario republicano compostelano La Defensa no seu n² (29XI-1913). Paradoxalmente, nesas datas Casimiro Torre ocupaba tamén a presidencia da Deputación provincial.

${ }^{29}$ El Eco de Santiago (5-IX-18).

${ }^{30}$ Boletín de la Federación Católico-Agraria de Santiago n5 (1-I-1919). Unha aproximación á historia da Escola de Veterinaria de Santiago en RODRÍGUEZ GARCÍA, M. (1990), Historia da Escola de Veterinaria de Santiago de Compostela (1882-1924), Universidade de Santiago.

${ }^{31}$ Boletín del Instituto de Reformas Sociales, diciembre de 1915. Non sabemos a que terceira Cámara pode referirse para a provincia da Coruña, con toda probabilidade a unha errata ou unha confusión cunha sociedade agraria que se denominase «Cámara» como era relativamente frecuente. De de feito ese mesmo ano son as Cámaras de Santiago e A Coruña as únicas que designan vocais para o Consejo Provincial de Fomento, en concreto a Santiago Casares e ó xurista A. García Ramos como suplente (El Eco de Santiago 15-I-15), e no Anuario Social de España de 1917 as únicas Cámaras mencionadas en toda Galicia son as da Coruña e Santiago. En outubro de 1916 celébrase por exemplo un concurso de gando en Lugo e entre as entidades organizadoras bótase en falta á Cámara (La Voz de Galicia 17-X-16).

"CUADERNOS DE ESTUDIOS GALLEGOS", Tomo XLVII, Fascículo 112, Santiago 2000. 
Ata este momento as Cámaras mantiveran unha aparente neutralidade ante o movemento agrarista, se ben o seu discurso técnico e de respeto pola orde establecida podía ter unha lectura contra determinadas tendencias, pero no clima de radicalización social posterior á Primeira Guerra Mundial van tomar partido abertamente a carón dos perceptores de foros, como veremos a continuación.

\section{AS CÁMARAS ANTE A CUESTIÓN FORAL: 1918-1923}

'O se iniciar o conflicto europeo podíanse dar por fracasados os diferentes intentos de dotar ó agrarismo galego dunha orientación común (Unión Campesina, Solidaridad Gallega, o Directorio Antiforista de Teis, a Acción Gallega de Basilio Álvarez). Os años bélicos suporán unha aparente calma, pero a partir de 1918 se multiplican as fundacións de sociedades agrarias, o abolicionismo sustitúe ó redencionismo como solución maioritaria para o conflicto foral e a Confederación Regional de Agricultores Gallegos de novo liderada por Basilio Álvarez rexistra grandes avances na coordinación dun movemento que deixa cada vez menos espacios sen cubrir na xeografía galega ${ }^{32}$. O impago das rendas forais xeneralízase, en especial nas dúas provincias meridionais, e ós embargos dos bens dos foratarios opónselles a resistencia dos veciños en aras da solidariedade parroquial, chegándose a extremos de tensión social que culminan en matanzas de campesiños como a de Guillarei (Tui) de 1922.

Ante esta conxuntura, aparecen (Pontevedra, Tui) organizacións de perceptores de rendas forais, que ata o momento non se dotaran de organizacións permanentes seguramente porque a solidez dos seus vencellos co estamento político as facía innecesarias. As Cámaras Agrícolas de Santiago e Pontevedra actúan tamén na práctica como organizacións de intereses dos foristas, e así a primeira celebra ó largo de 1922 reunións das que se derivan un telegrama ó Consello de Ministros protestando contra o acordo da corporación municipal de Pontevedra (a proposta dos concelleiros agrarios) en favor da abolición dos foros, visitas a varios deputa-

${ }^{32}$ CABO VILlaVERDE, M. (1998), O agrarismo, Vigo: Edicións A Nosa Terra, pp.113-148.

"CUADERNOS DE ESTUdios GALLEGOS", Tomo XLVII, Fascículo 112, Santiago 2000. 
dos recabando o seu apoio e unha circular en abril de $1922^{33}$. Nela lembra o seu carácter de organismo oficial, o que non lle impide tomar partido de xeito categórico contra «el estado anárquico de nuestros campos» e «la amenaza continua contra la propiedad», entre mencións á Revolución Rusa e denuncias da pasividade gobernamental e xudicial.

A Cámara de Pontevedra, pola súa banda, desperta do seu letargo para elaborar un informe sobre a cuestión foral en vistas ó enésimo proxecto de redención que circulaba polas Cortes. Os termos suxeridos pola Cámara beneficiarían claramente ós perceptores, como a non necesidade de presentar documentación por parte do forista (abondaría a mera constatación da observancia no pago por parte do foratario) ou que se declarase redimible o foro para ámbolos dous dominios, apoiando non sendo lixeiros detalles o proxecto de redención elaborado polo ministro e deputado conservador por Tui Mariano Ordóñez nun intento de reconducir a situación por cauces aceptables para os seus intereses e arrebatar esa bandeira á axitación agrarista ${ }^{34}$. A cuestión foral foise resolvendo nalgunas comarcas a base de acordos de redención negociados entre perceptores e organizacións agrarias, e con carácter global quedaría desactivada en 1926 co Decreto de Redención promulgado durante a Dictadura.

En 1919 producírase unha reorganización das Cámaras (R.D. 2-IX1919), na que salientaba o carácter obrigatorio da asociación (pasaría a voluntaria en 1921) para os contribuíntes da provincia que pagasen máis de 25 pta. por rústica ou pecuaria, que terían dereito a elexir por sufraxio ós directivos. Como secretario (art.17 $7^{\circ}$ designábase automaticamente ó Xefe da Sección Agronómica e como vocais natos ó do Servicio Forestal, ó Inspector Provincial de Hixiene Pecuaria e, de existir, ós presidentes das Federacións Agrarias. A acollida non foi en Galicia precisamente entusiasta. Os católicos, en plena expansión dos seus sindicatos, resaltan a inutilidade de tales institucións e sinalan o desatino da sindicación obrigatoria e que a dinámica das eleccións (confiada a alcaldes e gobernador)

${ }^{33}$ El Eco de Santiago (15 e 22-IV-22). Neses momentos a Cámara de Santiago contaba unicamente con 31 socios e o exiguo do seu capital (173 pta.) indica que a penas levaba a cabo ningunha das actividades que se propuxera; MINISTERIO DE FOMENTO (1924), La Acción social agraria en España, páx.40. A Cámara presentaría en xaneiro de 1923 ó Goberno o seu propio proxecto de redención foral.

${ }^{34}$ Galicia (28-III-23); El Ideal Gallego (3-IV-23).

"CUADERNOS DE ESTUDIOS GALLEGOS", Tomo XLVII, Fascículo 112, Santiago 2000. 
as condenaría ineludiblemente a convertirse en niños de caciquismo. Fronte ó intento de revitalizar as Cámaras, os social-católicos presentábanse como a xenuina representación dos intereses agrarios e esixían maior recoñecemento por parte da Administración ${ }^{35}$. Dende $A$ Nosa Terra, pola súa banda, os nacionalistas salientaban o seu carácter caciquil e que en cada unha das provincias os vocais non eran verdadeiros cultivadores e estaban ó servicio das respectivas redes de poder (riestristas en Pontevedra, bugallalistas en Ourense...) e eran na súa maioría alcaldes e deputados provinciais $^{36}$. Un personaxe da autoridade moral de Rodrigo Sanz, o que fora líder da Solidaridad Gallega, redactara xa un informe por encargo da Federación Agraria de Ferrol-Pontedeume en resposta ó cuestionario previo feito público pola Dirección Xeral de Agricultura, e de el se desprende que entre o agrarismo non confesional as Cámaras tampouco gozaban de gran consideración. Sanz negáballes a natureza de representación da agricultura porque «no son Asociaciones espontáneas, sino artificiosas de suyo y artificiales de hecho», polo seu carácter uniforme para todas as provincias e por terse reducido a instrumento de «Los cuatro o cinco caciques y vividores de la política a quienes interesó tener un órgano más y que al efecto inscribieron como asociados a cuarenta o cincuenta amigos pagadores de una cuota mensual como para un compromiso o chinchorrería social más». De novo as sociedades agrarias merecerían en opinión de Sanz a consideración de verdadeiras representantes dos agricultores por presentar as características opostas (espontaneidade, adaptación ó medio, participación masiva). A alternativa ás Cámaras debería pasar pois por unha aplicación máis xenerosa da Lei de Sindicatos

\footnotetext{
${ }^{35}$ No mesmo sentido o artigo de Alfredo García Ramos, que non esquezamos fora directivo da Cámara coruñesa anos atrás, no diario católico coruñés El Ideal Gallego, «La sindicación oficial» (6-IX-1919), onde critica a sindicación obrigatoria, vaticina que as Cámaras, instaladas nas capitais provinciais, só chegarán ó verdadeiro cultivador a través dos Concellos (o que lles garantiría a desconfianza dos campesiños) e lles contrapón a CNCA como verdadeira representación da agricultura. $\mathrm{O}$ mesmo xornal calificaba pouco despois o decreto de «habilidad caciquil, para asociar al labrador oficialmente, temerosos los oligarcas de que la asociación privada, cada día más pujante, diese al traste con los caciques grandes y pequeños» (El Ideal Gallego 12-X-1919).

${ }^{36}$ A Nosa Terra (25-X-1919). En Lugo o primeiro presidente da remozada Cámara Agrícola sería nada menos que José Benito Pardo, recoñecido máximo muñidor electoral da provincia.
}

"CUADERNOS DE ESTUdIOS GALLEGOS", Tomo XLVII, Fascículo 112, Santiago 2000. 
Agrícolas de 1906 e a representación das sociedades agrarias nos órganos da Administración relacionados coa agricultura e nas Corporacións locais por medio de concelleiros corporativos ${ }^{37}$.

Con todo, as dúas Federacións Católicas da provincia da Coruña (as de Santiago e Coruña) póñense de acordo coa Asociación General de Ganaderos del Reino para consensuar unha lista conxunta que propoñer ós votantes; nela destaca a presencia dos dous enxeñeiros agrónomos destinados na Granxa da Coruña (Hernández Robredo e Andrés Corral Castro), colectivo moi próximo tradicionalmente en Galicia ós católico-agra$\operatorname{rios}^{38}$. Tamén mediante esta candidatura o societarismo confesional tentaba reforzar a súa mensaxe de apoliticismo e de traballo pragmático e efectivo respaldado polos técnicos, en contraposición a outras tendencias dentro do agrarismo ó servicio segundo esta versión de intereses políticos espúreos e manipuladoras do campesiñado.

\section{AS CÁMARASAGRÍCOLAS ENTRE 1923 E A GUERRA CIVIL}

Os presaxios dos seus detractores verificáronse e as Cámaras Agrícolas pasaron sen pena nin gloria nin influencia efectiva nos procesos decisivos que tiveron lugar no agro galego ata a guerra civil. Como proba do desinterese xeneralizado cara a estas institucións, en 1924 o Gobernador Civil da Coruña multaba nada menos que a sesenta alcaldes (dous tercios do total) por non ter cumprimentado os trámites para a elección de vocais á Cámara Agrícola ${ }^{39}$. Tampouco estivo presente ningunha das Cámaras

\footnotetext{
${ }^{37} \mathrm{O}$ informe pode consultarse no periódico ferrolán La Voz de la Liga do 6 e 10-VI1917. Rodrigo Sanz rexeitaba tamén a sindicación obrigatoria («cosa inútil, dañosa, repugnante y delincuente») e apuntaba solucións de corte claramente corporativo como a designación polas sociedades agrarias de representantes nas Deputacións Provinciais e no Senado, que se convertiría así nunha Cámara corporativa extendendo o mecanismo polo que xa se elixían algúns senadores por parte das Sociedades Económicas e as Universidades.

${ }^{38}$ El Ideal Gallego (5-X-1919).

${ }^{39}$ Boletín Oficial de la Provincia (31-XII-1924). Para dous Concellos coñecemos datos das eleccións a vocalías da Cámara que só poden explicarse como froito dun desinterese compartido por autoridades municipais, electores e organizacións agrarias, pois no termo de Betanzos (uns 9.000 habitantes por esas datas) só exerceron o seu dereito ó
} 
galegas no Congreso de Economía de Galicia celebrado en Lugo en 1925, malia o seu carácter moito máis marcadamente oficial que as anteriores Asembleas Agrarias.

Na provincia da Coruña, apréciase como os agrarios católicos, pese á súa postura crítica, intentan controlar estas institucións, logrando colocar á súa fronte a Salvador Sanz, presidente da Federación Católico-Agraria coruñesa. O voceiro desta Federación pode anunciar igualmente en 1928 que «La Cámara Agrícola designó a personas afines a nuestra obra», de novo incluíndo a varios técnicos dos centros oficiales entre eles ${ }^{40}$. Non obstante, nos medios católico-agrarios seguiranse sinalando as súas deficiencias, e perante os pasos cara ó corporativismo que acomete a Dictadura propoñen a creación de Comités Paritarios Agrarios que sustituísen ás Cámaras e nos que o sindicalismo católico estaría sobrerrepresentado e recoñecida a súa valía como salvagarda contra a extensión de doctrinas subversivas do dereito de propiedade, xusto nun momento no que a Confederación Nacional Católico-Agraria se atopaba en crise tanto a nivel estatal como galego. Igualmente, foi o escepticismo a nota dominante nestes medios cando no frenesí lexislativo dos seus derradeiros anos a Dictadura

voto quince persoas (Arquivo Municipal de Betanzos, caixa 1.028) e no de Ames (7.600 habitantes en 1930) oito (Arquivo Municipal de Ames, caixa 760). Non dispoñemos do dato de cantos contribuíntes por rústica superaban neses Concellos as 25 pesetas, pero no de Teo (veciño ó de Ames) estaban nese caso en 1923 ó redor dun 30\%; DOMÍNGUEZ ALMANSA, A. (1997), A formación da sociedade civil na Galicia rural: asociacionismo agrario e poder local en Teo (1890-1940), Santiago: Concello de Teo e Xunta de Galicia, páx. 44.

${ }^{40}$ Galicia Agraria (15-V-1928). O dominio da Cámara Agrícola permitiu por exemplo ós social-católicos participar na toma de decisións dos investimentos en agricultura a nivel provincial porque lles garantía a presencia na Junta Administrativa Provincial de los Servicios Agrícolas (creadas por R.D. 22-X-1926 con labor de coordinación de tódolos organismos oficiais con competencias no fomento da agricultura). Pódese comprobar a través da consulta do libro de actas da Junta coruñesa, conservado no Arquivo do Centro de Investigacións Agrarias de Mabegondo. Ata 1930 sempre está presente un católico en representación da Cámara provincial xunto con diferentes técnicos oficiais, un vocal pola A.G.G.R. e un representante da Deputación. No caso de Lugo deducimos das conclusións da Asemblea de 1930 da FCA luguesa que os católicos non gozaban deste control da Cámara provincial, xa que a xulgan «sólo viva a la hora de las elecciones y cuya existencia y directivos fueron desconocidos para el Poder público durante varios años», ó tempo que se advertía contra calquera proxecto de facer obrigatoria a cuota (Galicia Social Agraria n ${ }^{\circ}$ 6, XII-1930).

"CUADERNOS DE ESTUdiOS GALLEGOS", Tomo XLVII, Fascículo 112, Santiago 2000. 
promulgou un Decreto creando as Cámaras de la Propiedad Rústica, en sustitución das Agrarias, que finalmente non sería aplicado ${ }^{41}$. O descrédito das Cámaras e a desconfianza do seu carácter oficial eran tan fortes polo tanto entre os medios católicos que en ningún momento foron consideradas ensaios ou pasos cara a organización corporativa que era unha das súas máis firmes propostas programáticas.

Durante o período republicano as Cámaras Agrícolas mantiveron en Galicia un perfil baixo ${ }^{42}$. As tendencias predominantes no agrarismo galego durante a República, e máis co devalo das Federacións Católicas (sobre todo no Sur de Galicia), reflectíronse na composición das Cámaras. Vexamos senón a circular pola que o Gobernador Civil nomeaba en marzo de 1937 unha Comisión Xestora formada case exclusivamente por técnicos por «[estar] constituida la Cámara Oficial Agrícola con elementos elegidos por Sindicatos que, los que no han sido disueltos por ministerio de las disposiciones vigentes del Gobierno Nacional, que son la mayoría, viven una existencia lánguida que desvirtúa su representación en aquel organismo». Nada mellor proba que o modelo de societarismo agrario sostido dende aAdministración ata 1931 a través entre outras institucións das Cámaras Agrícolas, convertérase nunha opción minoritaria no campo galego a finais da II República.

${ }^{41}$ A Xunta Directiva desta efémera Cámara na Coruña estaba sen embargo monopolizada por directivos social-católicos como Jacobo Varela de Limia, Emilio Romay, Juan Bugeiro ou Santos Bugallo (Galicia Agraria 1-I y 1-II-1930).

${ }^{42}$ Só podemos reseñar a organización dalgún concurso comarcal de productos hortícolas, a publicación dalgún que outro folleto de divulgación ou a adhesión ó Comité ProEstatuto de Autonomía, todo isto referido á Cámara da Coruña. Polo demais, as catro Cámaras elaboraron censos de sociedades e sindicatos agrarios para a súa participación nas eleccións a vocalías.

"CUADERNOS DE ESTUDIOS GALLEGOS", Tomo XLVII, Fascículo 112, Santiago 2000. 